\title{
Investigation on Transient Characteristics due to Lightning
}

\author{
Dr. K. V. Satyanarayana ${ }^{1}$, G. S. N. Raju ${ }^{2}$ \\ ${ }^{1}$ Professor, Dept. of ECE, Dadi Institute of Engineering and Technology, Ankapalle, \\ Visakhapatnam-531002, Andhra Pradesh \\ ${ }^{2}$ Professor, Dept. of ECE, Andhra University, Visakhapatnam-530003
}

\begin{abstract}
The behaviour of transient characteristics of the grounding grid due to lightning is investigated. The effect of permittivity and resistivity of the earth on such characteristics is consolidated. Simulation is carried out at high frequency using MATLAB. It is interesting to note that the permittivity has small influence and resistivity has considerable effect on transient response.
\end{abstract}

Keywords: Grounding grid, Lightning, Transient Voltages, Earth Permittivity, Earth Resistivity

\section{Introduction}

When lightning strikes an electric substation, large currents will flow in substation and electronic equipment before dissipating into the soil through the grounding system. The electromagnetic fields are generated by such lightning surges will produce large currents and voltages which may cause damage to the equipment and may be dangerous to the personnel working close by. Besides, modern electronic circuits generally have weak signal levels and are sensitive to different kinds of electromagnetic disturbances. The unwanted electromagnetic fields are induced by the lightning current may cause measurement error or result in damage to the electronic circuits. The grounding system is designed in such a way that the electromagnetic fields do not exceed tolerable levels. The tolerable levels are defined in several publications both in terms of safety [1,2] and equipment susceptibility [3-5].

Substation grounding grids are made of interconnected conductor rods, buried under substations. The use of the grids is to reduce the ground resistance of electric installations and smooth the potential gradient on the earth surface to ensure safety to the persons during short-circuit defects of the power system. The maximum step and touch voltages are computed to reduce the hazard .The grounding systems is designed to meet the requirement of safety and electrical properties. The decrease in the ground resistance is to reduce the rise of the potential around the grid, caused by the fault current emanating to the earth, so that the electromagnetic interference with the communication system nearby will be decreased [6].

Many papers have investigated the performance of grounding grid [14-16], they did not take account of the effect of the earth permittivity. This is true if the frequency of the injected current, the earth resistivity and the earth permittivity are low. If the earth relative permittivity is 100 and the earth resistivity is $1000 \Omega \mathrm{m}$, then the earth permittivity influence will be comparable with that of the earth resistivity when the frequency of the current is high. Even the earth permittivity still produces a few effects on the performance of grounding grid at low frequency; it may cause the transient performance of grounding grid greatly [8].

However, based on experimental results, it has been recognized for a long time that the soil resistivity and permittivity are strongly frequency dependent [17-21].

In this paper, the earth permittivity influence on the performance of grounding grids at high frequency and transient is analyzed. In order to take account of the earth permittivity, model of complex resistivity is used which is the combination of both the earth permittivity and the earth resistivity. Grounding grids with several earth parameters are analysed to show the influence.

It is observed that the impedance at low frequency is constant and resistive. At higher frequencies (more than 100 $\mathrm{KHz}$ ), the impedance will increase and it becomes inductive. For the highest frequencies, the effect of capacitance is dominant, mostly in soils with high permittivity. The permittivity of the soil has practically no influence on the ground impedance for frequencies lower than $500 \mathrm{kHz}$. Thus, the resistivity is determinant for all the cases and at low frequencies the impedance is directly proportional to the resistivity [7].

The influence of the soil relative permittivity is related to the capacitive coupling between the conductors of the grounding system since the soil is a dielectric medium. So, it is obvious that the influence of the soil permittivity is effective through the influence of the self and mutual capacitance of the grounding conductors on the transient behaviour of the grounding system [9].

The soil with lower resistivity, the conduction current is dominant, so the influence of the soil permittivity on the transient behaviour of the grounding system is neglected compared with the influence of the soil resistivity.

Keeping soil conductivity constant, soil permittivity variation does not have much influence on the transient response of the grounding system except in soils with extremely high resistivity. 


\section{International Journal of Science and Research (IJSR) \\ ISSN (Online): 2319-7064 \\ Index Copernicus Value (2013): 6.14 | Impact Factor (2014): 5.611}

The influence of the soil resistivity is more important than that of the soil permittivity. The influence of the soil permittivity on the transient behaviour of the grounding system in the soil with very high resistivity may be considered for better accuracy of results.

The resistivity and permittivity of certain soil (Tasikmalaya soil) will vary which depend on the percentage of water and also depend on the variation of injected frequency current [10].

The calculated GPR as a function of time is shown in fig.6. It is observed that relative permittivity has no major effect on the GPR for low soil resistivity (below $1000 \Omega \mathrm{m}$ ). However, for a resistivity of $10 \mathrm{k} \Omega \mathrm{m}$, it is observed that increasing the permittivity reduces the peak value of the GPR but increases the rise time, making the shape of the curve less sharp [11]

Measurement of the apparent permittivity of a soil provides a well-designed method of estimating its water content [12]. In nature, the most common polar liquid is water which has a relative permittivity of 80 , and for air 1 and for quartz 5 .

\section{Formulation}

The Green's function [22-23] is used to calculate the potential caused by a point source. For a point source in the earth as shown in fig. 1, the potential at any point in the earth can been calculated by solving the Laplacees equation with its boundary conditions.

$$
\begin{gathered}
\nabla^{2} \mathrm{~V}=0(1) \\
\text { As } \mathrm{z} \rightarrow \infty, \mathrm{V}_{\mathrm{K}} \rightarrow 0, \text { At } \mathrm{z}=-\mathrm{t}, \\
\frac{\partial \mathrm{V}_{1}}{\partial z}=0 \text {, At } \mathrm{m}^{\text {th }} \text { layer interfaces, } \mathrm{V}_{\mathrm{m}}=\mathrm{V}_{\mathrm{m}+1}, \\
\frac{1}{\rho_{m+1}} \cdot \frac{\partial \mathrm{V}_{\mathrm{m}}}{\partial z}=\frac{1}{\rho_{m}} \cdot \frac{\partial v_{m+1}}{\partial z} \mathrm{~m}=1,2,3, \ldots, \mathrm{K}-1 .
\end{gathered}
$$

Where $\rho_{i}$ is the resistivity of the $\mathrm{i}^{\text {th }}$ layer, $V_{i}$ is the potential in the $\mathrm{i}^{\text {th }}$ layer. By solving the Laplace's equation with boundary conditions, the formula for the potential at any point in the earth can be obtained [13].

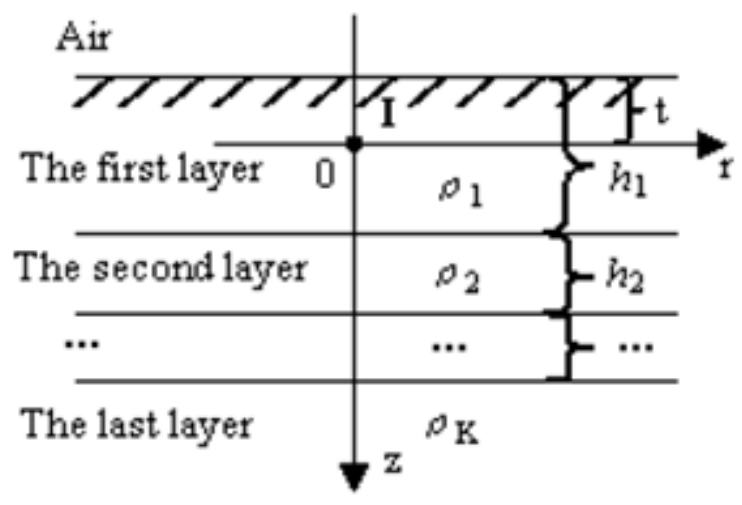

Figure 1: K-layer earth structure model.

In order to take account of the effect of the earth permittivity, model of complex resistivity is used which is the combination of both the earth permittivity and the earth resistivity. From the Maxwell ${ }^{e c}$ s first equation

$$
\nabla \times H=J+j \omega \varepsilon \mathrm{E}
$$

and the relationship between the current density and the electric field intensity

$$
\mathrm{J}=\frac{1}{\rho} \mathrm{E}
$$

We have

$$
\nabla \times H=\left(\frac{1}{\rho}+\mathrm{j} \omega \varepsilon\right) \mathrm{E}
$$

Where, $\mathrm{H}$ is the magnetic field intensity and $\mathrm{E}$ is the electric field intensity, $\mathrm{J}$ is the current density, $\rho$ and $\varepsilon$ are the earth resistivity and the earth permittivity. Let's introduce the concept of complex current density $\mathrm{J}$ ', is given by

$$
J^{\prime}=\left(\frac{1}{\rho}+j \omega \varepsilon\right) E
$$

Then, the complex resistivity is

$$
\rho^{\prime}=\frac{1}{\frac{1}{\rho}+j \omega \varepsilon}=\frac{\rho}{1+j \omega \varepsilon \rho}
$$

By using the complex resistivity in (1), the effect of the earth permittivity can be counted for when a grounding grid is analyzed.

When $\rho=10 \Omega \mathrm{m}, \rho=100 \Omega \mathrm{m}, \rho=1000 \Omega \mathrm{m}$, fig. 2 shows the variation of the complex resistivities with frequency if $\varepsilon_{\gamma}=$ 10 and $\varepsilon_{r}=100$.

From fig. 3 the following points are observed.

1) It is observed that when the earth permittivity is counted and the complex resistivity is introduced, great difference between the earth resistivity and the earth complex resistivity may takes place at some situations.

2) When the earth resistivity is low, it is almost equal to the earth complex resistivity even when the frequency is up to $1 \mathrm{MHz}$ and the earth relative permittivity is up to 100 .

3) When the earth relative permittivity is low, the earth resistivity is almost same with the earth complex resistivity.

4) At high frequencies, if the earth resistivity and the earth relative permittivity are larger, then there is a greater difference between the earth resistivity and the earth complex resistivity.

5) When $\rho=1000 \Omega \mathrm{m}, \varepsilon_{r}=100$, and the frequency is higher than $100 \mathrm{kHz}$, the difference between the earth resistivity and the earth complex resistivity is very large. This is due to effect of the earth permittivity. In this situation, the effect of the earth permittivity is taken into account when the grounding grid is analysed.

It is observed that when the earth resistivity is large, the influence of the earth permittivity on the performance of grounding grid at high frequency or transient is large.

The influence of earth permittivity is shown on both the performance at high frequency and transient of a $10 \mathrm{~m} \times 10 \mathrm{~m}$ grounding grid buried in the earth resistivity of $1000 \Omega \mathrm{m}$ with several earth permittivities and they are analyzed. The analysed grounding grid with a depth of $0.8 \mathrm{~m}$ is shown in fig.2. 


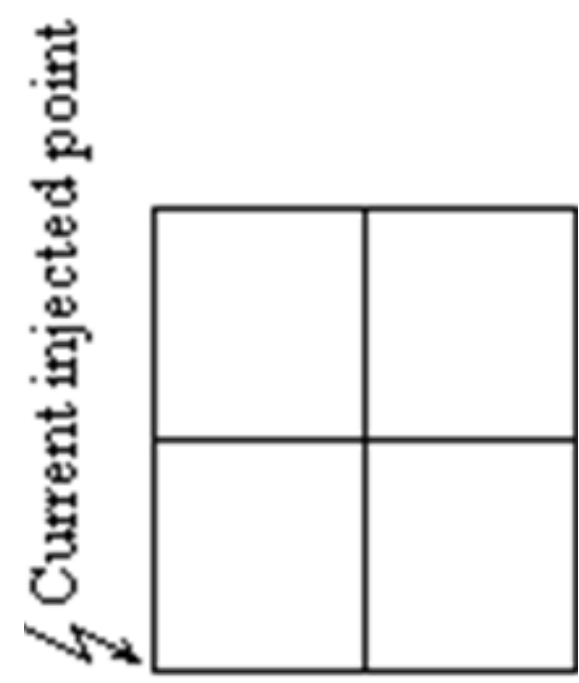

Figure 2: The grounding grid.

The transient performance is calculated with the help of the fast Fourier Transform when a lightning current shown in fig. 4 strikes the grounding grid directly.

The frequency response of the amplitude of the ground potential rise (GPR) at the current injected point is shown in the fig.5. The transient performance is shown in the fig. 6. It is observed from these characteristics that the GPR will increase with frequency if the earth permittivity is small. The GPR will decrease and vibrate with frequency if the earth permittivity is great. This is because the earth permittivity produces capacitance which will take effect in company with the mutual inductances among grounding segments at high frequency.

\section{Results and Conclusions}

The effect of the earth permittivity on the performance of grounding grid at high frequency and transient is analysed using MATLAB. Model of complex resistivity used, is the combination of both the earth resistivity and the earth permittivity.

If the earth permittivity and the earth resistivity are very large and the performance of the grounding grid at high frequency is analyzed, the effect of the earth permittivity is taken into account. It is observed that the permittivity has small influence and resistivity has considerable effect on transient response.

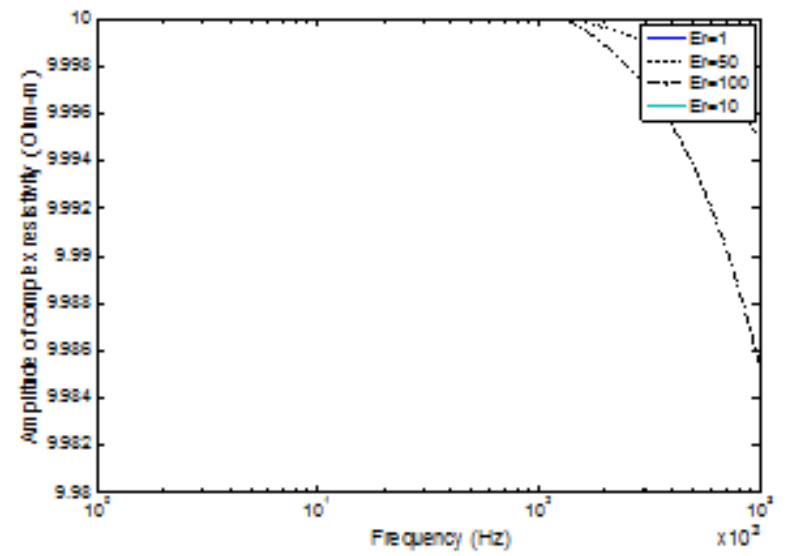

(a) $R=10 \Omega \mathrm{m}$

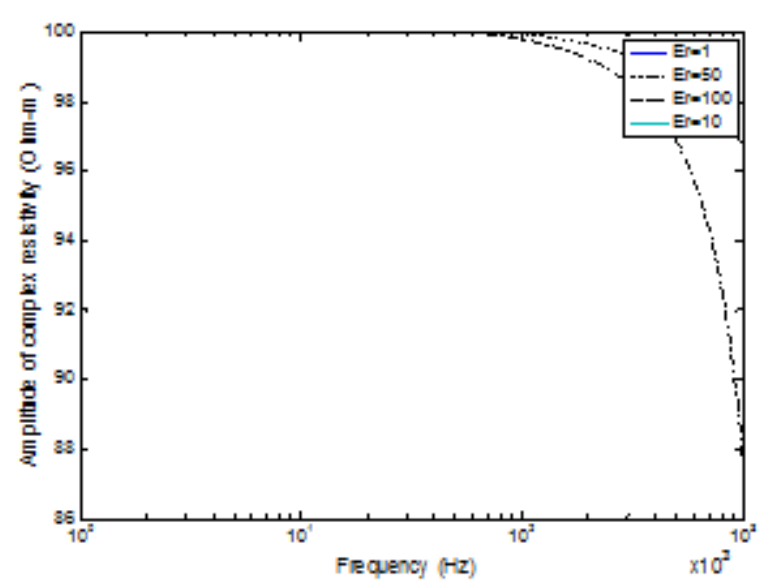

(b) $\rho=100 \Omega \mathrm{m}$

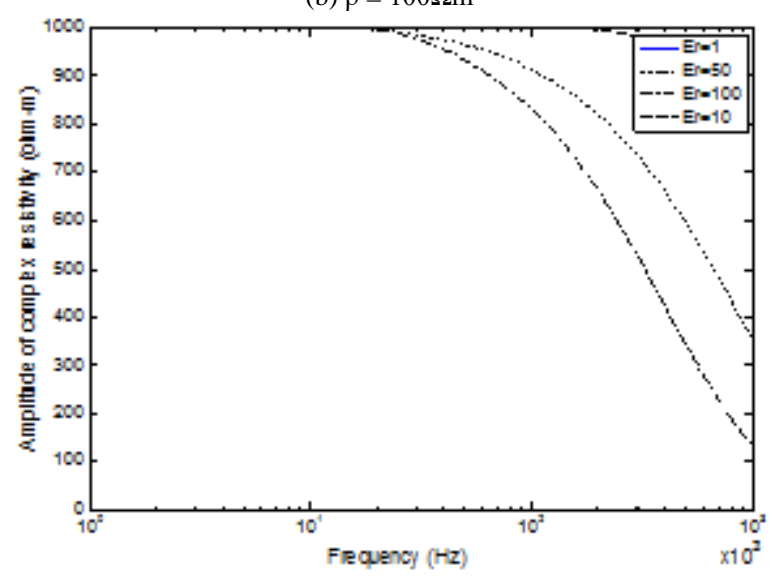

(c) $\rho=1000 \Omega \mathrm{m}$

Figure 3: Variation of Complex resistivity with frequency.

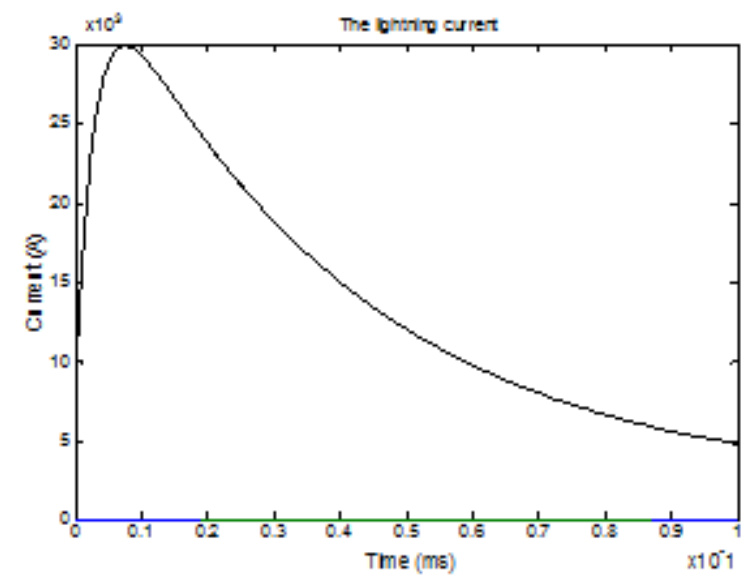

Figure 4: The lightning current.

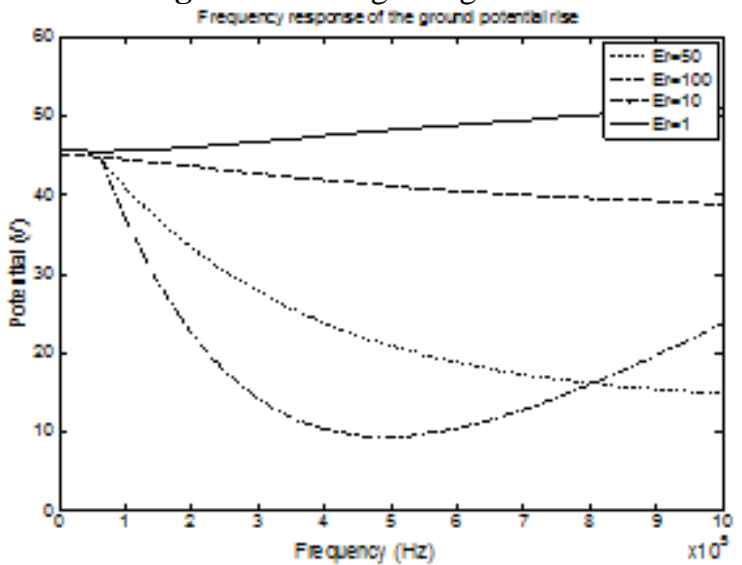

Figure 5: Frequency response of the ground potential rise 


\section{International Journal of Science and Research (IJSR) \\ ISSN (Online): 2319-7064}

Index Copernicus Value (2013): 6.14 | Impact Factor (2014): 5.611

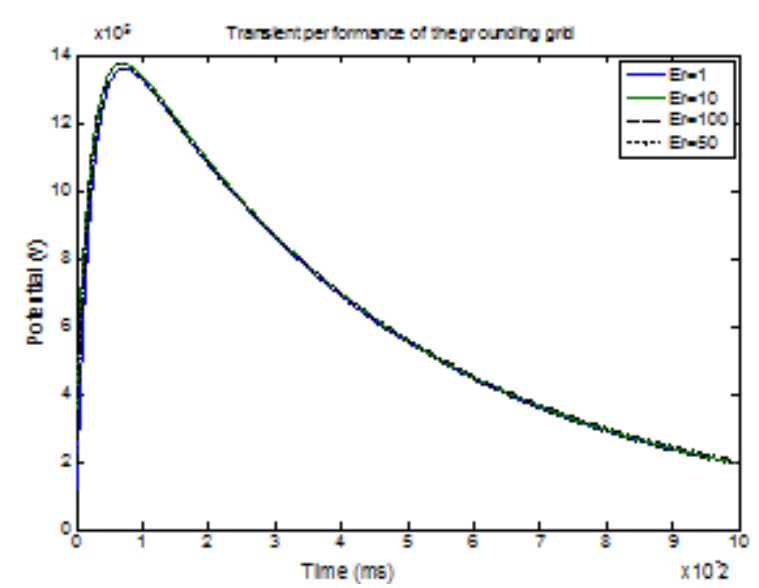

Figure 6: Transient performance of the grounding grid.

\section{References}

[1] "Effects of Current Passing through the Human Body, part 1, General Aspects", IEC 479-1, 1984; "Part 2, Special Aspects", IEC 479-2, 1984.

[2] „Electrical Shock Safety Criteria”, Proceedings of The First International Symposium on Electrical Shock Safety Criteria, Pergamon Press Inc, 1985, N.Y. (book).

[3] "Shielding Design - Methodology and Procedures", DWC Inc., 1986 (book).

[4] H.W.Denny, "Grounding for the Control ojEMI", DWC Inc., 1983 (book).

[5] A.Gleenwood, ,Electrical Thnsients in Power Systems”, 8, J.Wiley \& Sons, Inc., 1991, (book).

[6] Jiansheng Yuan, Huina Yang, Liping Zhang, Xiang Cui, and Xinshan Ma "Simulation of Substation Grounding Grids with Unequal-Potential", IEEE Transactions on Magnetics, Vol. 36, No. 4, July 2000, pp 1468-1471.

[7] A. F. Otero, J. Cidras, and C. Garrido, "Frequency analysis of grounding systems," in Proc. 8th Int. Conf. Harmonics Quality Power, 1998, vol. 1, pp. 348-353.

[8] Li QIAN, Yukuan JIANG, "Numerical Analysis of Earth Permittivity Influence on the Transient Performance of Grounding Grids", 7th Asia-Pacific International Conference on Lightning, November 1-4, 2011, Chengdu, China, pp.994-997.

[9] Y. Liu, M. Zitnik, and R. Thottappillil,“An improved transmission-line model of grounding system," IEEE Trans. Electromagn. Compat., vol. 43, no. 3, pp. 348355, Aug. 2001.

[10] Bambang Anggoro, Ngapuli I. Sinisuka, Parouli M. Pakpahan, "The Influence of Resistivity and Dielectric Constant of Soil Which is Injected by Low to High Current Frequency," IEEE Transactions 2006, pp.912915.

[11] Elmghairbi, A.; Haddad, A.; Griffiths, H.; , "Potential rise and safety voltages of wind turbine earthing systems under transient conditions," Electricity Distribution.20th International Conference and Exhibition on , vol., no., pp.1-4, 8-11 June 2009.

[12]D.A. Robinson*, C.M.K. Gardner, J.D. Cooper, "Measurement of relative permittivity in sandy soils using TDR, capacitance and theta probes: comparison, including the effects of bulk soil electrical conductivity", Journal of Hydrology 223 (1999) 198211.
[13] Takehiko Takahashi, Taro Kawase, "Calculation of earth resistance for a deep-driven rod in a multi-layer earth structure", IEEE Transactions on Power Delivery, vol. 6, pp. 608-614, Apr.1991

[14]F. P. Dawalibi, "Electromagnetic fields generated by overhead and buried short conductors, part 2- ground conductor," IEEE Transaction on Power Delivery, vol. 1, pp. 112-119, Oct.1986.

[15] A. P. S. Melipoulos, "An Advanced Computer Model for Grounding System Analysis," IEEE Transaction on Power Delivery, vol. 8, pp. 13- 23, Jan. 1993.

[16] Jiansheng Yuan, Huina Yang, Liping. Zhang, "Simulation of Substation Grounding Grids with Unequal-Potential," IEEE Trans. on Magn., vol. 36, pp. 1468-1471, July 2000.

[17] R. L. Smith-Rose, "The electrical properties of soils for alternating currents at radiofrequencies," Proc. Roy. Soc., vol. 140, no. 841 A, pp. 359-377, 1933.

[18] J. H. Scott, "Electrical and magnetic properties of rock and soil," in U.S. Geol. Surv., Dept. Interior, Washington, D.C., 1966.

[19]C. L. Longmire and K. S. Smith, "A universal impedance for soils," Topical Rep. for period July 1September 30, Defense Nuclear Agency, Santa Barbara, CA, 1975.

[20] S. Visacro and C. M. Portela, "Soil permittivity and conductivity behaviour on frequency range of transient phenomena in electric power systems," presented at the Symp. High Voltage Eng., Braunschweig, Germany, 1987.

[21]C. M. Portela, "Measurement and modeling of soil electromagnetic behavior," in Proc. IEEE Int. Symp. Electromagn. Compat., Seattle, WA, 1999, pp. 1004 1009.

[22]Zhong-Xin Li, Ke-Li Gao, Yu Yin, Cui-Xia Zhang and Dong Ge, "Numerical calculation for lightning response to grounding systems buried in horizontal multilayered earth model based on quasi-static complex image method", pp. 393-418.

[23]Z. X. Li and W. J. Chen, "Numerical simulation grounding system buried within horizontal multilayer earth in frequency domain", Communications in Numerical Methods in Engineering.-2007, vol. 23, no. 1, pp. 11-27.

\section{Author Profile}

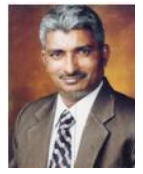

Dr. G.S.N. Raju received his B.E., M.E. with distinction and first rank from Andhra University and Ph.D. from IIT, Kharagpur. He is Professor of Electronics and Communication Engineering in $\mathrm{AU}$ College of Engineering, Andhra University Visakhapatnam, India. He is in teaching and research for the last 30 years in Andhra University. He guided 22 Ph.D.s in the fields of Antennas, Electro Magnetics, EMI/EMC and Microwave, Radar Communications, Electronic circuits. Publishe about 160 technical papers in National/International Journals/Conference Journals and transactions. He is the recipient of The State Best Teacher Award" from the Government of Andhra Pradesh in 1999, "The Best Researcher Award" in 1994, "Prof. Aiya Memorial National IETE Award" for his best Research guidance in 2008 and Dr. Sarvepalli Radhakrishnan Award for the Best Academician of the year 2007, He was a visiting Professor in the University of Paderborn and also in the University Karlsruhe, Germany in 1994. At present he holds 


\section{International Journal of Science and Research (IJSR) \\ ISSN (Online): 2319-7064}

Index Copernicus Value (2013): 6.14 | Impact Factor (2014): 5.611

the positions of Vice-Chancellor, Andhra University, Visakhapatnam, Andhra Pradesh, India, Chief Editor of National Journal of Electromagnetic Compatibility. Prof. Raju has published five textbooks Antennas and Wave Propagation, Electromagnetic Field Theory and Transmission Lines, Electronics Devices and Circuits, Microwave Engineering, Radar Engineering and Navigational Aids. Prof. Raju has been the best faculty performer in Andhra University with the performance index of 99.37.

Prof. K. V. Satyanarayana did his B.Tech. from Nagarjuna University and M.Tech. from Andhra University, Visakhapatnam. He is at present, Research Scholar, Dept. of ECE, A.U. College of Engg. (A), Andhra University, Visakhapatnam, Andhra Pradesh and he is working for his $\mathrm{PhD}$ under the guidance of Prof.G.S.N Raju. His research work is in the fields of EMI/EMC. 